\title{
Causes and consequences of individual variation in territory size in the American red squirrel
}

\author{
Todd D. Steury and Dennis L. Murray
}

Steury, T. D. and Murray, D. L. 2003. Causes and consequences of individual variation in territory size in the American red squirrel. - Oikos 101: 147-156.

For most territorial species that defend food or other resources, territory size is inversely related to resource density. However, in some food-based territorial species, larger territories are known to contain greater absolute resource availability. For these latter species, both the specific determinants of territory size, and the relationship between territory size and fitness, remain unclear. We predicted that in American red squirrels (Tamiasciurus hudsonicus), where larger territories tend to hold increased food resources, survival should be correlated positively with territory size and that both individual (body mass, sex, duration of territory ownership) and habitat-specific (population density) attributes would contribute to variation in territory size. We monitored survival and territory size of 58 squirrels during a two-year period using live-trapping and radio-telemetry. Survival and territory size were correlated positively, with each 0.1 ha decrease in territory size typically resulting in a $16.6 \%$ increase in mortality risk; mortality risk for squirrels with the smallest versus largest territories differed by up to 23 -fold. Territory size was negatively related to local population density, but not to any attributes of individual squirrels, implying that, in this species, territory size may not be influenced strongly by individual quality. We conclude that while larger territories may confer a survival advantage to squirrels, territory size is unrelated to individual physical attributes, likely because costs associated with the acquisition of a larger or richer territory outweigh potential benefits of increased food access.

T. D. Steury and D. L. Murray, Dept of Fish and Wildlife Resources, Univ. of Idaho, Moscow, ID 83844-1136, USA. Present address for TDS: Dept of Life Sciences, Indiana State Univ., Terre Haute, IN 47809, USA (Issteury@scifac.indstate.edu). Present address for DLM: Dept of Biology and Environmental and Resource Studies Program, Trent Univ., Peterborough, ON, Canada K9L $1 Z 6$.

For many species, the size of individual territories varies considerably both among and within habitats (Smith 1968, Gill and Wolf 1975, Kodric-Brown and Brown 1978, Mares and Lacher 1987, Turpie 1995). Traditional models of territory size optimization (for species exhibiting food-based territoriality) suggest that variation in territory size should be caused, at least in part, by variation in resource abundance (reviewed by Adams 2001). In support of these model predictions, many empirical studies have found inverse correlations between territory size and resource densities (Gass et al. 1976, Seastedt and MacLean 1979, Smith and Shugart 1987, Turpie 1995). These results have led to the predic- tion that all territories should be similar in terms of per capita resource levels, and that individuals should occupy an ideal free distribution across the landscape (Brown 1969, Fretwell and Lucas 1970, Milinski and Parker 1991). Indeed, for many species, territories within and across habitats appear to have approximately the same absolute amount of available food resources (Gill and Wolf 1975, Gass et al. 1976, Kodric-Brown and Brown 1978), implying that territory owners respond adaptively to food abundance by adjusting territory size to balance the costs of territory maintenance with the gains associated with territory ownership (Hixon 1980, Schoener 1983).

Accepted 1 October 2002

Copyright (C) OIKOS 2003

ISSN 0030-1299 
In some species that exhibit food-based territoriality, however, the above model appears not to hold, in that resources are distributed homogeneously and yet considerable disparity exists in individual territory sizes (Smith 1968, Norman and Jones 1984, Mares and Lacher 1987, Lacher and Mares 1996). Thus, for such species, larger territories tend to have greater absolute amounts of energetic resources. For example, the amount of food algae available to individual pomacentrid reef fish (Parma victoriae) appears to be correlated positively with territory size (Norman and Jones 1984), while chipmunk (Tamias striatus) territory size correlates positively with the basal area of mast producing trees, an index of seed production in an area (Mares and Lacher 1987, Lacher and Mares 1996). In American red squirrels (Tamiasciurus hudsonicus), territory size appears to be correlated positively with the number of pine cones contained in the territory (pine seeds are the squirrel's main food source, especially over winter), and the absolute amount of food energy available to individual animals (Smith 1968). These findings imply that for these species, disparity in territory size should result in differential resource availability between individuals.

The results from such studies raise two important questions regarding variation in individual territory size. First, if larger territories have greater absolute amounts of available resources, then is the fitness (product of survival and reproduction) of the occupant also a function of territory size? Given that many studies have documented relationships between demographic variables and resource abundance (reviewed by Martin 1987 and Boutin 1990), a relationship between territory size and fitness seems intuitive. Yet, few studies to date have documented associations between territory size and either survival or fecundity in species exhibiting food-based territoriality (see Hixon 1980 for discussion of territory size and fitness in breeding-based territoriality). Second, to what extent do covariates other than food help further explain variation in territory size? Undoubtedly, some territory size variation is explained by variation in conspecific population densities (Adams 2001). Yet, disparity in individual quality may further contribute to variation in individual territory size, especially if fitness is a function of territory size. In such circumstances, individuals should benefit from increasing the size of their territories (i.e. maximize their fitness) and thus, territory size should be related to factors associated with an individual's ability to maintain and defend a larger territory. For example, body mass, sex, and territorial experience are attributes that may increase an individual's potential to win contest competitions (Kodric-Brown and Brown 1978, O’Neill 1983, Wauters and Dhondt 1989, 1992, Haley 1994, Stuart-Smith and Boutin 1994). If fitness is a function of territory size, attributes that enable an individual to occupy a larger territory should be subject to strong selective pressure.*
In this study, we examined the potential causes and consequences of individual variation in territory size in the American red squirrel. Given the previously documented relationship between territory size and absolute resource abundance in this species (Smith 1968), we predicted that squirrel fitness should be correlated positively with territory size. Although the relationship between territory size and fecundity (percent entering estrus, percent impregnated, average litter size, etc.) has not been analyzed in this species, previous research has demonstrated that fecundity largely is independent of resource abundance (Larsen et al. 1997, Becker et al. 1998, Humphries and Boutin 2000). Thus, herein we specifically focused on the relationship between territory size and survival. Also, we evaluated if squirrel physical attributes facilitated the acquisition and maintenance of larger territories. Previous studies of conspecific interactions in red squirrels found that the outcome of territorial disputes were positively associated with territory ownership, body mass, and male gender (although males are heavier than females and thus the role of mass vs gender remains unclear, StuartSmith and Boutin 1994, see also Wauters and Dhondt 1989, 1992). Thus, we predicted that body mass and duration of past territory ownership would be correlated positively with territory size, and that males would have larger territories than females.

\section{Methods}

We studied squirrels on four, 10-hectare study areas in the Clearwater National Forest, Idaho $\left(46^{\circ} \mathrm{N}, 114^{\circ} \mathrm{W}\right)$, during May 1998-May 2000. Two study areas were lower elevation (1000 m.a.s.1.) mature timber stands composed predominantly of red cedar (Thuja plicata) and grand fir (Abies grandis), with white pine (Pinus monticola), Douglas fir (Pseudostuga mensezii), lodgepole pine ( $P$. contorta), and Engelmann spruce (Picea engelmannii) also present at lower densities. The two remaining study areas were higher elevation $(1600 \mathrm{~m})$ mature timber stands characterized by roughly uniform abundance of lodgepole pine, Engelmann spruce, and sub-alpine fir (Abies lasciocarpa). Peripheral and internal grid lines on each study area were established to facilitate trapping and mapping of territories.

We live-trapped squirrels (National Live Trap Corp., Tomahawk, WI) on each study area at least once every season (winter = Jan. - Mar., spring = April-June, summer $=$ July - Sept., autumn $=$ Oct. - Dec.). All capture and handling procedures were approved by the Animal Care and Use Committee of the Univ. of Idaho (Protocol \# 9029). Trapped squirrels were marked with ear tags (No. 1, National Band and Tag Co., Newport, $\mathrm{KY}$ ), weighed, and fitted with mortality-sensitive radiocollars (approximate mass $=8 \mathrm{~g}$, life-span $=6$ months; 
Telemetry Solutions, Concord, CA). Squirrels whose mass was $<170 \mathrm{~g}$ were classified as juveniles (Kemp and Keith 1970, Klenner and Krebs 1991); because only 1 juvenile was captured that exhibited territorial behavior, we excluded this individual from our analysis. Sex was determined by perineum length (Kemp and Keith 1970). We monitored daily survival of radio-collared animals using a handheld antenna and receiver (Advanced Telemetry Solutions, Isanti, MN). If a transmitter signal was lost, we located a potentially dispersing animal through intensive trapping and telemetry monitoring. Deceased individuals were located promptly to verify mortality and determine the proximate cause of mortality. Individuals were considered to have died only when mortality could be confirmed (carcass found, radio-collar found intact, etc.). For descriptive purposes, annual survival rates of various cohorts were calculated using [(1 - number of mortalities/number of radiodays $)^{365}$ (Trent and Rongstad 1974).

Although some variation in resource distribution undoubtedly existed across territories in a study area, the distribution of cone energy should have been relatively homogenous across territories given that the tree density and composition within a study area were largely uniform (Wirsing et al. 2002a). However, in order to verify that the absolute amount of resources on each territory was a positive function of territory size, we measured the size and quality of squirrel cone caches (middens) during the months of October and/or November. Middens typically are fixed in position, and thus increases in territory size often are accompanied by an increase in the number of middens that the territory contains (Price et al. 1986, Boutin and Schweiger 1988, Larsen and Boutin 1995). Therefore, we enumerated the number of middens contained on each territory. We also generated an index of the energetic value of each midden from the product of the number of cones visible in the midden, counted by species, and the average energetic value of cones of that species (Gurnell 1984, Setterington and Keppie 1997). To determine the energy available per cone for each species, a sample of cones ( $n=3$ to 30 for the different tree species) was collected from middens. The number of seeds per cone was enumerated, and seeds from each cone were dried and weighed to determine average dry mass per seed (Smith 1968, Setterington and Keppie 1997). The energy per gram of dry seed was then determined using bomb calorimetry. In addition, we measured midden area, which was used as a relative index of the number of cones stored from present and previous years (Rusch and Reeder 1978, Gurnell 1984). Finally, we also gave each midden a subjective index of quality (range: 110 ), relative to other middens in that habitat, based upon its size, number of visible cones, and evidence of past and present use (e.g. fresh cone bracts, depth of bracts, number of holes, etc.; Larsen et al. 1997).
The territory boundaries of each study animal were determined at the beginning of each season using radiotelemetry and behavioral observations (Price et al. 1986, Larsen and Boutin 1994). We collected at least 15 perimeter locations from each squirrel for territory mapping purposes (Price et al. 1986, Larsen and Boutin 1995). Territory maps were digitized and territory size was determined using the maximum convex polygon (Price et al. 1986, Boutin and Schweiger 1988). We recorded the duration of time (in 3-month seasons) that each squirrel occupied its territory. For squirrels that occupied a territory at the beginning of the study (summer 1998), we assumed that such individuals had owned that territory for at least 3 seasons, given that territories generally are established during the fall influx of juveniles, and few squirrels change territories once they become established (Smith 1968, Price et al. 1986, Larsen and Boutin 1995). This assumption was corroborated by the fact that we recorded only one new territory settler (out of 58 squirrels) during winter over the course of our two-year study.

Population density often is a strong predictor of territory size (Adams 2001). Thus, we determined the density of squirrels on each study area seasonally using trapping, visual and auditory counts, and territory mapping. This procedure enabled enumeration of virtually all individuals on each study area (i.e. a complete census; Rusch and Reeder 1978, Davis and Winstead 1980). For our population estimates, we only included squirrels that occupied middens located inside the study area boundaries. Additionally, because squirrels likely require a territory for breeding and over-winter survival (Smith 1968, Kemp and Keith 1970, Larsen and Boutin 1994, Stuart-Smith and Boutin 1994), only territory owners were included in census results.

\section{Data analysis}

We used information theoretic methods to assess the importance of territory size as a factor influencing survival in our system (Burnham and Anderson 1998); similar methods were used to determine the factors influencing territory size. Information theoretic methods evaluate the relative strength of multiple models of the relationships between dependent and explanatory variables by ranking those models according to the fit of the data to the model, relative to the number of parameters in the model (Anderson et al. 2000). Because mass, sex, time, or study area may be important covariates of survival in squirrels and other species (Wauters and Dhondt 1989, Tavecchia et al. 2001, Murray 2002, Wirsing et al. 2002b), we tested all possible models of survival containing linear combinations of territory size and/or each of these variables (Table 1 ); in all, 32 models of survival were examined. Similarly, we tested all possible models relating linear com- 
Table 1. Top ten models (as well as constant only model) of factors influencing survival of squirrels in our system, as ranked by $\mathrm{AIC}_{c}$. For each model $i, K_{i}$ is the number of parameters in the model ("area" is represented by 3 dummy-coded variables), $\Delta_{i}$ is the change in $\mathrm{AIC}_{c}$ between the model and the "best" model (i.e. model with the lowest $\mathrm{AIC}_{c}$ ), $w_{i}$ is the Akaike weight, and $\theta_{i}$ is the coefficient estimate of the effect of territory size on survival. $R_{L}^{2}$ is the $R^{2}$ analog for models analyzed using maximum likelihood techniques.

\begin{tabular}{|c|c|c|c|c|c|c|}
\hline Model $_{i}$ & $K_{i}$ & $\Delta_{i}$ & $w_{i}$ & $R_{L}^{2}$ & $\theta_{i}$ & $\operatorname{SE}\left(\theta_{i}\right)$ \\
\hline area + sex + mass + territory size & 8 & 0.00 & 0.160 & 0.169 & -1.95 & 0.76 \\
\hline area + mass + territory size & 7 & 0.11 & 0.151 & 0.153 & -2.02 & 0.71 \\
\hline sex + mass + territory size & 5 & 0.40 & 0.131 & 0.122 & -1.03 & 0.68 \\
\hline sex + mass & 4 & 0.95 & 0.100 & 0.104 & - & - \\
\hline area + territory size & 6 & 1.57 & 0.073 & 0.129 & -2.44 & 0.73 \\
\hline time + sex + mass + territory size & 10 & 1.79 & 0.065 & 0.188 & -1.51 & 0.82 \\
\hline time + mass + territory size & 9 & 2.20 & 0.053 & 0.170 & -1.36 & 0.72 \\
\hline time + area + territory size & 11 & 2.89 & 0.038 & 0.196 & -2.47 & 0.79 \\
\hline time + area + mass + territory size & 12 & 3.16 & 0.033 & 0.211 & -2.11 & 0.78 \\
\hline time + sex + mass & 9 & 3.51 & 0.028 & 0.161 & - & - \\
\hline constant only & 2 & 12.72 & 0.000 & 0 & - & - \\
\hline
\end{tabular}

binations of mass, sex, and number of seasons of territory ownership to territory size (Table 2). Because population density often is the primary determinant of territory size (Adams 2001), we included the number of squirrels occupying each study area as a possible covariate in these latter models. Thus, 16 models of the determinants of territory size were examined. We did not include any interaction terms in either our survival or determinants of territory size models, because we had no a priori reason to believe that such interactions existed, and because we wanted to limit the number of models examined (Burnham and Anderson 1998, Anderson et al. 2000).

The relative strength of each model was examined using Akaike's Information Criterion, corrected for small sample sizes (AIC ; $_{c}$ Burnham and Anderson 1998, Anderson et al. 2000). Akaike weights $\left(w_{i}\right)$, an index of the strength of a model relative to all models

Table 2. All possible models of factors influencing squirre territory size, as ranked by $\mathrm{AIC}_{c}$. For each model $i, K_{i}$ is the number of parameters in the model, $\Delta_{i}$ is the change in AIC between the model and the "best" model (i.e. model with the lowest $\mathrm{AIC}_{c}$ ), and $w_{i}$ is the Akaike weight. The variable "duration" refers to the duration of time the squirrel has occupied the territory.

\begin{tabular}{lllll}
\hline Model $_{i}$ & $K_{i}$ & $\Delta_{i}$ & $w_{i}$ & $R^{2}$ \\
\hline density & 3 & 0.000 & 0.300 & 0.408 \\
density + mass & 4 & 0.865 & 0.195 & 0.415 \\
density + mass + duration & 5 & 1.781 & 0.123 & 0.421 \\
density + duration & 4 & 1.894 & 0.116 & 0.410 \\
density + sex & 4 & 2.119 & 0.104 & 0.409 \\
density + mass + sex & 5 & 2.829 & 0.073 & 0.416 \\
density + mass + sex +duration & 6 & 3.612 & 0.049 & 0.422 \\
density + sex + duration & 5 & 4.051 & 0.040 & 0.410 \\
constant only & 2 & 62.479 & 0.000 & 0.000 \\
sex & 3 & 64.083 & 0.000 & 0.004 \\
duration & 3 & 64.096 & 0.000 & 0.004 \\
mass & 3 & 64.555 & 0.000 & 0.000 \\
sex + duration & 4 & 65.757 & 0.000 & 0.008 \\
mass + duration & 4 & 66.211 & 0.000 & 0.004 \\
mass + sex & 4 & 66.220 & 0.000 & 0.004 \\
mass + sex + duration & 5 & 67.807 & 0.000 & 0.009 \\
\hline
\end{tabular}

considered, and the change in $\mathrm{AIC}_{c}$ between models $(\Delta$ $\mathrm{AIC}_{c}$ ) were used to assess the strength and uncertainty of selected models (Buckland et al. 1997, Burnham and Anderson 1998). The strength of individual explanatory variables as predictors of the dependent variable was assessed by examining the sum of Akaike weights for models containing that variable, as well as the modelaveraged coefficient estimate and unconditional standard error (Burnham and Anderson 1998, Anderson et al. 2000). Akaike weights and model-averaged coefficient estimates are sensitive to model uncertainty, and thus provide unbiased estimates of effect and error that are not conditional upon the chosen model.

In order to examine relationships between explanatory variables (including territory size) and survival, we generated models of squirrel mortality rates using Poisson regression. Poisson regression is a parametric procedure in which the dependent variable is a count or rate, and a Poisson distribution is used to draw statistical inference (Fleiss 1981, Frome and Checkoway 1985, Selvin 1995). Thus, in our survival analyses, the dependent variable was daily mortality rate calculated from radio-telemetry data; each datum in the regression was the fate of the animal (live or dead) offset by the number of days of observation (Murray 2002, Wirsing et al. 2002b). However, our survival and territory data were stratified by season in order to account for potential temporal variability; a squirrel season was one 90-day period for which the territory size, mass, and fate of one squirrel were determined. Individuals for which the fate was unknown were right-censored in the analysis (Lee 1992). The best fit of each Poisson regression equation to the data was generated using the maximum likelihood method. Finally, we calculated an $R^{2}$ analog $\left(R_{L}^{2}\right)$ for each survival model in order to assess the amount of variation in survival that was explained by each model (Hosmer and Lemeshow 1989, Menard 1995, 2000).

Models explaining the effect of body mass, sex, and duration of territory ownership on territory size were 
generated using linear regression. Least squares methods were used to determine the best fit of each regression equation to the data for these models. Unless otherwise noted, all estimates are accompanied by $95 \%$ confidence intervals or $95 \%$ confidence limits.

\section{Results}

Fifty-eight squirrels were studied over 123 squirrel seasons. We noted considerable variability in the territory sizes of monitored animals: sizes averaged $0.76 \pm 0.08$ hectares ( $n=123$ squirrel seasons) and ranged from 0.25 to 1.99 ha across all study areas and over the duration of the study. Even within habitats and timeperiods, however, individual territory size ranged by as much as $1.65 \mathrm{ha}$, and the mean difference between the largest and smallest territories on a study area was $0.72 \pm 0.19$ ha ( $n=22$ study area $\mathrm{x}$ time combinations). The median number of middens per territory was 1 , but ranged from 1 to 7 ; midden area averaged $269.7 \pm 48.2$ $\mathrm{m}^{2}$ (range $=5-1325 \mathrm{~m}^{2} ; n=109$ territories). Finally, the average density of squirrels across all study areas was $7.1 \pm 1.6$ squirrels/10 ha and ranged from 1 to 13 squirrels/10 ha.

Of the 58 squirrels for which territories were mapped, 23 died over the course of 7196 radio days, providing an overall estimate for the annual rate of survival of 0.31 ( $0.18-0.47 ; 95 \%$ confidence limits). Annual survival rate for females over the course of the study was 0.38 (0.19-0.58); for males was $0.23(0.08-0.49)$. Annual survival rates for each study area were: 0.48 (0.17-0.78), $0.49(0.21-0.76), 0.06(0.01-0.32)$, and $0.23(0.04-0.53)$. The survival rate for the first year of the study was $0.45(0.23-0.72)$, while for second was $0.21(0.08-0.43)$. Eighteen of the 23 mortalities were documented predation events; predation was suspected in the remaining 5 mortalities, but could not be confirmed (Wirsing et al. 2002b).

\section{Territory size and resource abundance}

Larger territories apparently contained greater absolute amounts of cone energy. We found that territory size was correlated positively with midden area; with each 0.1 ha increase in territory size, total midden area increased by $46.2 \pm 7.8 \mathrm{~m}^{2}$ (midden area $=-13.1+$ $462.8 \times$ territory size; $r=0.78, P<0.001)$. Our subjective score of midden size also was correlated positively with territory size (midden score $=1.4+8.9 \times$ territory size; $r=0.73, P<0.001)$. We also determined that each 0.5 ha increase in territory size generally resulted in one $(1.04 \pm 0.08)$ extra midden being contained in the territory (number of middens $=0.17+2.08 \times$ territory size; $r=0.75, P<0.001)$. While we failed to detect a relationship between territory size and visible cone energy contained in the midden $(P=0.25)$, we did note that some squirrels cached considerably more cones underground than did others (especially those with large numbers of cones on their territories), which undoubtedly affected our ability to ascertain precisely the number of cones contained in each squirrel midden.

\section{Effect of territory size on survival}

Our analysis suggested that territory size was an important determinant of squirrel survival (Table 1). The best survival model included explanatory variables for study area, mass, sex, and territory size, and explained 16.9\% of the variation in survival (Table 1). The Akaike weight $\left(w_{1}\right)$ for this model, however, suggested that the probability that this model was best among the set of models considered was low (Table 1), causing suspicion regarding the model's superiority. However, the sum of Akaike weights for all models containing territory size equaled 0.80 , suggesting that among the models considered, the model that was truly best had a relatively high probability of containing a variable for territory size. Most importantly, the model-averaged coefficient estimate for the effect of territory size on survival $(-1.81 \pm 1.72 ; \pm$ unconditional $95 \%$ C.I. $)$ suggested that the effect of territory size on survival was statistically and biologically significant. The coefficient estimate, converted to a rate ratio $\left(1-\mathrm{e}^{-1.81 / 10}\right)$, suggested that for each 0.1 ha increase in territory size, a squirrel's risk of mortality decreased by $16.6 \%$.

In order to verify post-hoc that survival was a linear function of territory size, we converted the continuous variable for territory size into 6 categories of territory size and replaced the continuous variable in the best model with the dummy-coded categorical variable for territory size (Hosmer and Lemeshow 1989). We then assessed the relationship between the coefficient estimates for each dummy-coded category and the mean territory size of each category. The relationship between the coefficient estimates and our categories of territory size may not have been linear (Fig. 1). However, a hyperbolic transformation of the continuous variable for territory size (1/territory size) failed to improve the fit of the best model $\left(\mathrm{AIC}_{c}\right.$ increased by 1.684).

Given that we were interested in the effect of individual variation in territory size on squirrel survival within, rather than across habitats, we compared the Akaike weights for models containing both study area and territory size, with that for models containing territory size but not study area. Models with territory size and study area were generally better than those lacking study area ( $w$ for model's with area $=0.64 ; w$ for models without area $=0.36$ ). The model correlating survival with territory size alone had a qualitatively worse fit than the model with no variables at all 


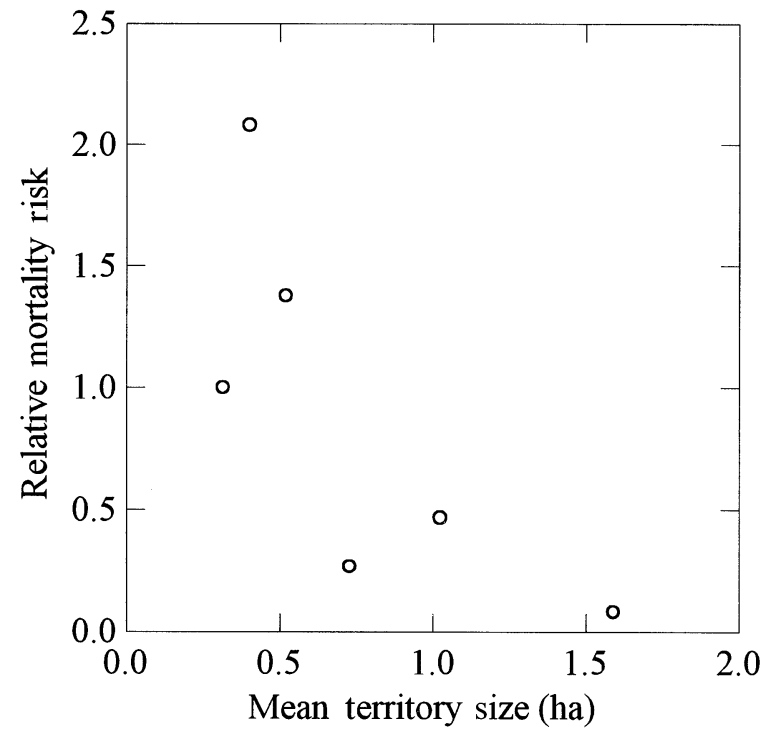

Fig. 1. Relationship between territory size (broken into 6 dummy-coded categories) and the relative risk of mortality. Estimates were generated using the survival model that returned the lowest $\mathrm{AIC}_{c}$ value (Table 1).

$\left(\Delta \mathrm{AIC}_{c}=0.54\right)$. Yet, the best model contained both study area and territory size (Table 1 ), and the model containing just study area and territory size ranked fifth of 32 models tested $\left(\Delta \mathrm{AIC}_{c}\right.$ from best model $=1.57$; $\left.w_{5}=0.07\right)$. Thus, our results suggest that survival likely was correlated with territory size within, rather than across habitats, and thus that site-specific factors also contributed to squirrel survival.

\section{Determinants of individual territory size}

Our analyses suggested that neither body mass, sex, nor the duration of time a territory had been occupied influenced individual squirrel territory size (Table 2 and 3, Fig. 2). The best model explaining territory size included only the variable for population density, but not those representing mass, sex, or duration of territorial occupation; this model explained $40.8 \%$ of the variation in territory size (Table 2). The sum of Akaike weights for all models containing the sex, mass, or duration of occupation equaled only $0.27,0.44,0.33$, respectively, suggesting that among the models considered, the model that was truly best had a relatively low probability of containing one or more of these variables. The sum of Akaike weights for models containing the variable for population density equaled 1.0, suggesting that the model that was truly best (among those considered) surely contained this variable. Furthermore, the model-averaged coefficient estimates and unconditional standard errors for the variables representing individual squirrel quality suggested that none of these variables had a statistically significant effect on territory size (Table 3). Lack of significance appeared to be caused by lack of effect rather than low statistical power; coefficient estimates suggested that territory size increased by only $0.002 \pm 0.003$ and decreased by $0.02 \pm 0.04$ hectares for each 1 -gram increase in mass, and each season of additional territorial experience, respectively. Thus, the difference in territory size between the lightest (175 g) and heaviest (269 g) squirrels in our system would be only 0.20 ha, and the difference in territory size between squirrels that had a newly acquired territory and squirrels that had occupied their territory for a year or more would be typically less than 0.10 ha. Coefficient estimates also indicated that female squirrels had territories that were $0.02 \pm 0.13$ ha larger than male territories, on average. Thus, territory size in our system appears to be determined primarily by population density; for each 1 squirrel/10 ha increase in population density, territory sizes tended to decrease by $0.09 \pm 0.02$ ha. Therefore, territories on study areas with the highest and lowest squirrels densities would differ in size by approximately 1 ha (i.e. $131 \%$ of the mean territory size). Although the relationship between population density and territory size may be non-linear (Fig. 2), a hyperbolic transformation of population density (1/pop. density) did not improve the fit of the best model $\left(\mathrm{AIC}_{c}\right.$ increased by 39.75$)$.

\section{Discussion}

Our results suggest that American red squirrels with larger territories had higher survival rates than those with smaller territories. According to model-averaged

Table 3. Estimates of effect for factors included in models of squirrel territory size. The model averaged coefficient estimate $(\theta)$ is the average coefficient estimate from all models containing that variable, weighted by each model's Akaike weight. The unconditional standard error of $\theta$ is a similarly-weighted measure that incorporates both uncertainty in the coefficient estimate and uncertainty in the chosen model (Anderson et al. 2000). The confidence interval was calculated using the unconditional $\operatorname{SE}(\theta)$.

\begin{tabular}{lccc}
\hline Variable & Model averaged $\theta$ & Unconditional SE $(\theta)$ & $95 \%$ C.I. \\
\hline Population density & -0.085 & 0.0093 & $-0.103--0.067$ \\
Mass & 0.0021 & 0.0017 & $-0.0012-0.0054$ \\
Sex & -0.020 & 0.067 & $-0.152-0.111$ \\
Duration of occupation & -0.016 & 0.021 & $-0.057-0.024$ \\
\hline
\end{tabular}



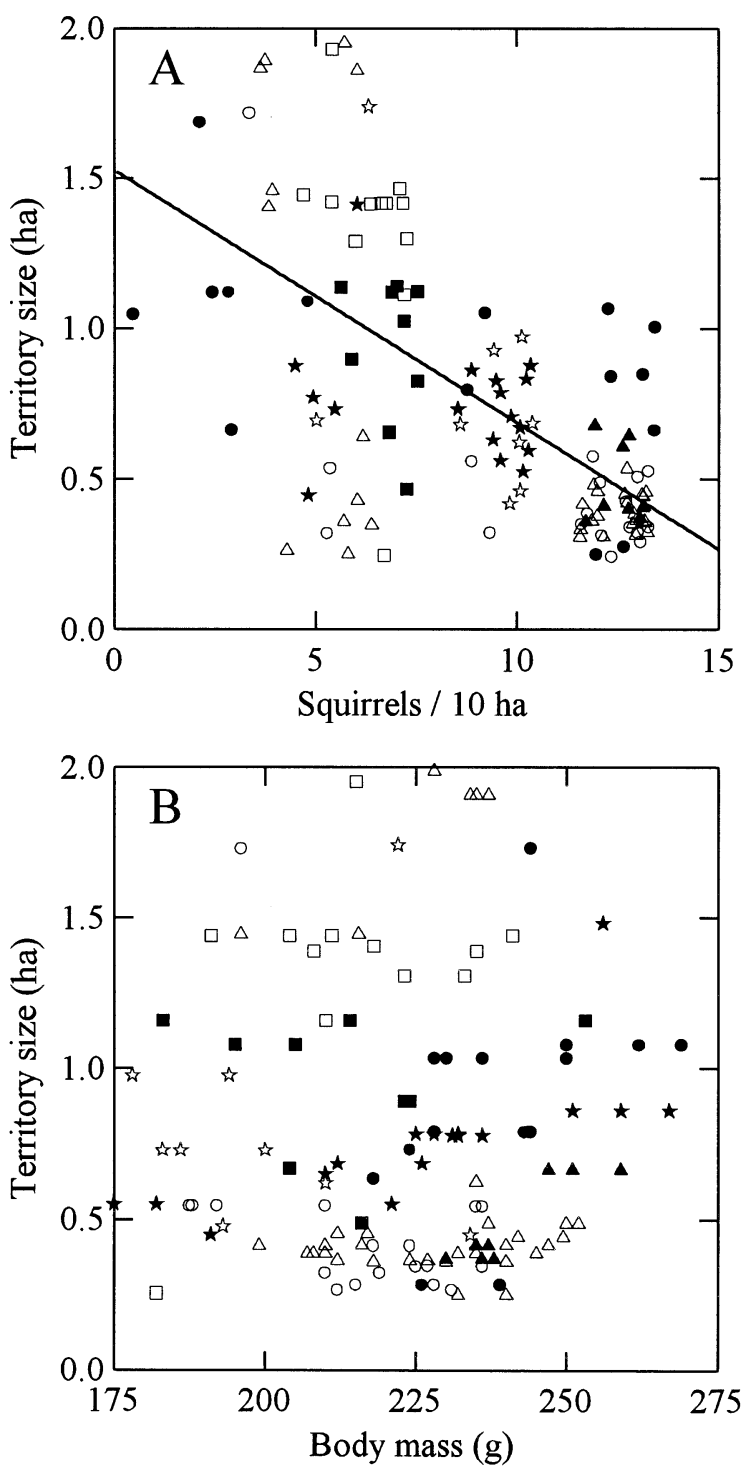

Fig. 2. Relationships between territory size and A) squirrel density, and B) body mass grouped by study area and sex. The different shapes represent the different study areas, while closed or open symbols represent males or females, respectively. The line in graph A represents the best model of the determinants of territory size (population density only). The data points in A have a slight random jitter to facilitate viewing, and each datum is representative of a squirrel-season rather than of an individual squirrel.

coefficient estimates, squirrels with the smallest recorded territories were approximately 23 times more likely to die than those with the largest territories. Even within time-periods and habitats, differences in the size of squirrel territories appeared to augment mortality risk by as much as 20 -fold. Because of our observational rather than experimental approach, we cannot confirm that an increase in territory size causes a direct increase in survival. However, an experimental ap- proach to this question likely would be difficult to implement for most territorial species, given the problems associated with identifying and manipulating the factors that directly impact territory size. Although squirrels that survived through a given season often increased their territory size in response to the death of neighboring squirrels, we correlated survival throughout a season with territory size at the beginning of that season. Thus, our results support the conclusion that survival was dependent upon territory size, rather than the idea that better survival enabled animals to occupy larger territories.

The majority of squirrel mortalities in our study were due to predation. However, intuitively one might predict that risk of predation should increase with increasing territory size (Covich 1976, Eason and Stamps 1992). Thus, the negative correlation between mortality (predation) and territory size observed in this study deserves explanation. We suggest that squirrels with smaller territories had fewer resources available to them, and therefore either had to spend more time searching for food (thereby increasing their risk of predation), or else faced nutritional limitation (which could increase their vulnerability to predation, Wirsing et al. 2002b). Given that territory size influenced survival while accounting for the effects of mass (i.e. nutrition), and that territory size was not correlated with mass, we would speculate that occupants of small territories spent a greater amount of time looking for food. Future research on this topic could correlate squirrel territory size with winter activity budgets to determine if smaller territory size begets higher activity and increased predation risk.

For many food-based territorial species, one might not expect a relationship between fitness and territory size. This prediction stems from the fact that per capita resource abundance often appears to be equal and independent of territory size (Gill and Wolf 1975, Gass et al. 1976, Kodric-Brown and Brown 1978, Turpie 1995). Instead, territory size is negatively associated with resource density. An inverse relationship between resource density and territory size is intuitively appealing; if an area has relatively low resource density, then the individual occupying that area needs a larger territory to achieve a desired energetic gain. Furthermore, an area with a relatively low resource density typically also has a lower population density. Thus, an individual occupying the latter area experiences lower intruder pressure, and therefore does not require additional time or energy to effectively maintain or defend a larger territory. The result is that all territories contain approximately the same absolute amount of energetic resources and require roughly the same amount of energy to defend. Under these circumstances, fitness should not be a function of territory size.

In a few species, however, researchers have failed to detect relationships between resource densities and ter- 
ritory size, but instead have found positive associations between territory size and absolute resource abundance (Smith 1968, Norman and Jones 1984, Mares and Lacher 1987, Lacher and Mares 1996). Furthermore, additional studies of these species sometimes have led researchers to suggest the presence of a territory size - fitness relationship. For example, Larsen and Boutin (1994) found that juvenile squirrels that obtained territories relatively far from their mothers often had larger territories with traditional (well-used) middens, and that these individuals were more likely to survive their first winter. Similarly, Smith (1968), using calculations of energetic requirements, suggested that squirrels with the smallest territories probably had insufficient resources to survive over winter; his prediction was supported empirically. The difference between systems where food density influences territory size, and systems where territory size is unrelated to resource density, may be a function of the degree of territoriality that a particular species exhibits. In species with non-contiguous or overlapping territories, where the costs of territory maintenance and defense are relatively low, adjusting the size of one's territory to meet energetic goals is readily feasible. However, for species with contiguous and non-overlapping territories, occupants should have limited ability to increase the size of their territories because of the presence of neighboring conspecifics (Hixon 1980, Norman and Jones 1984, Adams 2001). Similarly, highly territorial individuals may be unwilling to decrease the size of their territories in response to increased resource density because of temporal variability in the density of those resources (Rusch and Reeder 1978, Lima 1984). Thus, in species with contiguous territories, the size of individual territories should not be associated strongly with resource density, and larger territories may contain greater absolute amounts of resources. In a review of experimental studies of the determinants of territory size, Adams (2001) found that in species with contiguous territories, population density usually was the prime determinant of territory size, and resource density often was unimportant. Thus, although further studies are needed to determine how extensively territory size is correlated with survival across species, and how territory size, survival, and fecundity may interact to affect an individual's fitness, future studies of the fitness consequences of territory size should include in particular species with contiguous, nonoverlapping territories.

Given the observed relationship between territory size and survival in American red squirrels, characteristics that enable territory owners to acquire and maintain larger territories should be subject to strong selective pressure. Previous researchers often have found that territory size is a function of individual quality (Simon 1975, Kodric-Brown and Brown 1978,
Krebs 1982, O’Neill 1983, Haley 1994). However, our data did not support the prediction that individual quality should influence territory size in American red squirrels; neither mass, sex, nor duration of territory ownership was correlated strongly with territory size. We cannot rule out the possibility that other individual traits that were not measured may have influenced territory size. However, we suggest that territory size in this species may be largely random with respect to individual quality; potentially superior squirrels may not attempt to acquire a larger or richer territory because the costs of doing so may outweigh the benefits of increased food abundance. The acquisition and ownership of a territory is of such prime importance in this species (squirrels that do not own a territory do not breed and probably fail to survive the winter, Larsen and Boutin 1994 and Stuart-Smith and Boutin 1994), that squirrels typically must settle on the first unoccupied territory they encounter and then generally retain that territory for an extended period of time (Larsen and Boutin 1994, 1995). Furthermore, although squirrels can switch or expand their territories over winter as neighboring squirrels die, the costs associated with switching to a new territory likely are high (Larsen and Boutin 1994). Thus, few squirrels abandon a controlled territory in order to acquire a larger or richer territory (Price et al. 1986, Larsen and Boutin 1995), and the expansion of a territory is often associated with bequeathal of the annexed habitat to offspring (Price and Boutin 1993, Boutin et al. 2000). Even in male squirrels, any increase in territory size during the non-breeding season typically is lost with the fall influx of juveniles (Smith 1968, Rusch and Reeder 1978). Finally, although squirrels that are more aggressive may be able to expand their territories prior to the onset of winter, such aggressive interactions likely incur heavy costs including undue energetic expense, risk of injury, or increased risk of predation (Stuart-Smith and Boutin 1994, T. Steury, unpubl.). The costs of territory switching or expansion probably exceed the relatively large observed effect of territory size on squirrel mortality risk. Only under such circumstances should the optimal strategy for American red squirrels be to accept the size of an acquired territory, even if the size is small and hence confers an increased mortality risk.

Acknowledgements - We are grateful to K. Larsen for providing instruction on trapping, handling, and studying American red squirrels, and E. Strand for assistance with GIS software. We would also like to thank P. Cook, A. Gall, and A. Wirsing for field assistance. We are especially grateful to K. Bourke, who played an integral role in the mapping of territories, and to B. Dennis, J. Sullivan and A. Wirsing for comments on the manuscript. This study was funded by the Idaho Department of Fish and Game and the U.S. Forest Service. We thank D. Davis and W. Melquist for providing the opportunity to study red squirrel population ecology in Idaho. 


\section{References}

Adams, E. S. 2001. Approaches to the study of territory size and shape. - Annu. Rev. Ecol. Syst. 32: 277-303.

Anderson, D. R., Burnham, K. P. and Thompson, W. L. 2000 Null hypothesis testing: problems, prevalence, and an alternative. - J. Wildl. Manage. 64: 912-923.

Becker, C. D., Boutin, S. and Larsen, K. W. 1998. Constraints on first reproduction in North American red squirrels. Oikos 81: 81-92.

Boutin, S. 1990. Food supplementation experiments with terrestrial vertebrates: patterns, problems, and the future. Can. J. Zool. 68: 203-220.

Boutin, S. and Schweiger, S. 1988. Manipulation of intruder pressure in red squirrels (Tamiasciurus hudsonicus): effects on territory size and acquisition. - Can. J. Zool. 66: $2270-2274$

Boutin, S., Larsen, K. W. and Berteaux, D. 2000. Anticipatory parental care: acquiring resources for offspring prior to conception. - Proc. R. Soc. Lond. B 267: 2081-2085.

Brown, J. L. 1969. Territorial behavior and population regulation in birds. - Wilson Bull. 81: 293-329.

Buckland, S. T., Burnham, K. P. and Augustin, N. H. 1997. Model selection: an integral part of inference. - Biometrics 53: 603-618.

Burnham, K. P. and Anderson, D. R. 1998. Model selection and inference: a practical information-theoretic approach. - Springer-Verlag.

Covich, A. P. 1976. Analyzing shapes of foraging areas: some ecological and economic theories. - Annu. Rev. Ecol. Syst. 7: $235-257$

Davis, D. E. and Winstead, R. L. 1980. Estimating the number of wildlife populations. - In: Schemnitz, S. D. (ed.), Wildlife management techniques manual. The Wildlife Society, pp. 221-245

Eason, P. K. and Stamps, J. A. 1992. The effect of visibility on territory size and shape. - Behav. Ecol. 3: 166-172.

Fleiss, J. L. 1981. Statistical methods for rates and proportions. - John Wiley and Sons.

Fretwell, S. D. and Lucas, H. J., Jr. 1970. On territorial behavior and other factors influencing habitat distribution in birds. - Acta Biotheor. 19:16-36.

Frome, L. E. and Checkoway, H. 1985. Use of Poisson regression models in estimating rates and ratios. - Am. J. Epidemiol. 121: 309-323.

Gass, C. L., Angehr, G. and Centa, J. 1976. Regulation of food supply by feeding territoriality in the rufous hummingbird. - Can. J. Zool. 54: 2046-2054

Gill, F. B. and Wolf, L. L. 1975. Economics of feeding territoriality in the golden-winged sunbird. - Ecology 56 $333-345$.

Gurnell, J. 1984. Home range, territoriality, caching behaviour and food supply of the red squirrel (Tamiasciurus hudsonicus fremonti ) in a subalpine lodgepole pine forest. - Anim. Behav. 32: 1119-1131

Haley, M. P. 1994. Resource-holding power asymmetries, the prior residence effect, and reproductive payoffs in male northern elephant seal fights. - Behav. Ecol. Sociobiol. 34: 427-434.

Hixon, M. A. 1980. Food production and competitor density as the determinants of feeding territory size. - Am. Nat. 115: $510-530$

Hosmer, D. W. and Lemeshow, S. 1989. Applied logistic regression. - Wiley.

Humphries, M. M. and Boutin, S. 2000. The determinants of optimal litter size in free-ranging red squirrels. - Ecology 81: 2867-2877.

Kemp, G. A. and Keith, L. B. 1970. Dynamics and regulation of red squirrel (Tamiasciurus hudsonicus) populations. Ecology 51: 763-779.

Klenner, W. and Krebs, C. J. 1991. Red squirrel population dynamics. I. The effect of supplemental food on demography. - J. Anim. Ecol. 60: 961-978.
Kodric-Brown, A. and Brown, J. H. 1978. Influence of economics, interspecific competition, and sexual dimorphism on territoriality of migrant rufous hummingbirds. - Ecology 59: 285-296.

Krebs, J. R. 1982. Territorial defense in the great tit (Parsus major): do residents always win? - Behav. Ecol. Sociobiol. 11: $185-194$

Lacher, T. E., Jr. and Mares, M. A. 1996. Availability of resources and use of space in eastern chipmunks, Tamias striatus. - J. Mammal. 77:833-849.

Larsen, K. W. and Boutin, S. 1994. Movements, survival, and settlement of red squirrel (Tamiasciurus hudsonicus) offspring. - Ecology 75: 214-223.

Larsen, K. W. and Boutin, S. 1995. Exploring territory quality in North American red squirrels through removal experiments. - Can. J. Zool. 73: 1115-1122.

Larsen, K. W., Becker, C. D., Boutin, S. and Blower, M. 1997. Effects of hoard manipulations on life history and reproductive success of female red squirrels (Tamiasciurus hudsonicus). - J. Mammal. 78: 192-203.

Lee, E. T. 1992. Statistical methods for survival data analysis - John Wiley and Sons.

Lima, S. 1984. Territoriality in variable environments: a simple model. - Am. Nat. 124: 641-655.

Mares, M. A. and Lacher, T. E., Jr. 1987. Social spacing in small mammals: patterns of individual variation. - Am. Zool. 27:293-306.

Martin, T. E. 1987. Food as a limit on breeding birds: a life-history perspective. - Annu. Rev. Ecol. Syst. 18: $453-$ 487.

Menard, S. 1995. Applied logistic regression analysis. - Sage

Menard, S. 2000. Coefficients of determination for multiple logistic regression analysis. - Am. Stat. 54: 17-24.

Milinski, M. and Parker, G. A. 1991. Competition for resources. - In: Krebs, J. R. and Davies, N. B. (eds) Behavioural ecology: an evolutionary approach. Blackwell, pp. $137-168$

Murray, D. L. 2002. Differential nutritional status and vulnerability to predation in snowshoe hares. - J. Anim. Ecol. 71: $614-625$.

Norman, M. D. and Jones, G. P. 1984. Determinants of territory size in the pomacentrid reef fish, Parma victoriae. - Oecologia 61: 60-69.

O'Neill, K. M. 1983. Territoriality, body size, and spacing in males of the bee wolf Philanthus basilaris (Hymenoptera; Sphecidae). - Behaviour 86: 295-321.

Price, K. and Boutin, S. 1993. Territorial bequeathal by red squirrel mothers. - Behav. Ecol. 4: 144-150.

Price, K., Broughton, K., Boutin, S. and Sinclair, A. R. E. 1986. Territorial size and ownership in red squirrels: response to removals. - Can. J. Zool. 64: 1144-1147.

Rusch, D. A. and Reeder, W. G. 1978. Population ecology of Alberta red squirrels. - Ecology 59: 400-420.

Schoener, T. W. 1983. Simple models of optimal-territory size - a reconciliation. - Am. Nat. 121: 608-629.

Seastedt, T. R. and MacLean, S. F., Jr. 1979. Territory size and composition in relation to resource abundance in Lapland longspurs breeding in arctic Alaska. - Auk 96:131-142.

Selvin, S. 1995. Practical biostatistical methods. - Duxbury Press.

Setterington, M. A. and Keppie, D. M. 1997. Jack pine cone quality and cache sizes of red squirrels in southern New Brunswick, Canada. - Can. J. Zool. 75: 332-335.

Simon, C. A. 1975. The influence of food abundance on territory size in the iguanid lizard Sceloporus jarrovi. Ecology 56: 993-998.

Smith, C. C. 1968. The adaptive nature of social organization in the genus of three squirrels Tamiasciurus. - Ecol. Monogr. 38: 31-63.

Smith, T. M. and Shugart, H. H. 1987. Territory size variation in the ovenbird: the role of habitat structure. - Ecology 68 : 695-704. 
Stuart-Smith, A. K. and Boutin, S. 1994. Costs of escalated territorial defense in red squirrels. - Can. J. Zool. 72: $1162-1167$.

Tavecchia, G., Pradel, R., Boy, V. et al. 2001. Sex- and age-related variation in survival and cost of first reproduction in greater flamingos. - Ecology 82: 165-174.

Trent, T. T. and Rongstad, O. J. 1974. Home range survival of cottontail rabbits in southwestern Wisconsin. - J. Wildl. Manage. 38: 459-172.

Turpie, J. K. 1995. Non-breeding territoriality: causes and consequences of seasonal and individual variation in grey plover Pluvialis squatarola behavior. - J. Anim. Ecol. 64: 429-438.
Wauters, L. and Dhondt, A. A. 1989. Body weight, longevity and reproductive success in red squirrels (Sciurus vulgaris). - J. Anim. Ecol. 58: 637-651.

Wauters, L. and Dhondt, A. A. 1992. Spacing behaviour of red squirrels, Sciurus vulgaris: variation between habitats and the sexes. - Anim. Behav. 43: 297-311.

Wirsing, A. J., Steury, T. D. and Murray, D. L. 2002a. A demographic analysis of a southern snowshoe hare population in a fragmented habitat: evaluating the refugium model. - Can. J. Zool. 80: 169-177.

Wirsing, A. J., Steury, T. D. and Murray, D. L. 2002b. Relationship between body condition and vulnerability to predation in red squirrels and snowshoe hares. - J. Mammal. 83: 707-715. 